Open Access

\title{
Does mobile instant messaging facilitate social presence in online communication? A two-stage study of higher education students
}

\author{
Ying Tang ${ }^{1 *}$ and Khe Foon Hew ${ }^{2}$
}

\footnotetext{
* Correspondence: yt11@iu.edu 'School of Informatics, Computing, and Engineering, Indiana University, Myles Brand Hall 210, 901 E 10th Street, Bloomington, IN 47408, USA Full list of author information is available at the end of the article
}

\begin{abstract}
Online social presence supports student learning by making group interactions more appealing and has become a central concept in computer-mediated communication. However, questions remain over how social presence is presented in a mobile instant messaging (MIM)-facilitated environment and to what extent MIM can afford social presence compared to a threaded discussion forum. This study offers a new contribution by examining the social presence levels afforded by a MIM app (WeChat) and comparing it with a threaded discussion forum. We present a two-stage study. In stage 1, we analyzed social presence levels in the MIM postings of class A with a validated instrument comprising three dimensions, namely, affective, interactive, and cohesive responses. In stage 2 , we employed a historical cohort control experimental research study to compare social presence levels manifested in class A to those in class B who used an online forum. Follow-up interviews were conducted to solicit explanations of the differences in social presence levels. The results show that compared to the asynchronous threaded forum, the quasi-synchronous MIM is particularly suited to promoting (a) expression of emotions (affective social presence), (b) expressing agreement (interactive social presence), and (c) phatics and providing support (cohesive social presence). Four attributes might contribute to the differences including (a) the ease of use of non-verbal cues, (b) location-free digital interaction, (c) presence awareness, and (d) multimodality. The implications for future practices and research are discussed.
\end{abstract}

Keywords: Mobile instant messaging, Forum, Online communication, Social presence

\section{Introduction}

The contemporary education paradigm supports the use of social learning environments in which students are given opportunities to interact with one another via the Internet. One common technological platform where student communication occurs is threaded asynchronous forums. Asynchronous online discussion frees learners from time and space constraints (Gao, Zhang, \& Franklin, 2013) and provides ample opportunities for perusal, interaction, and reflection (Gerosa, Filippo, Pimentel, Fuks, \& Lucena, 2010). In a

(c) The Author(s). 2020 Open Access This article is licensed under a Creative Commons Attribution 4.0 International License, which permits use, sharing, adaptation, distribution and reproduction in any medium or format, as long as you give appropriate credit to the original author(s) and the source, provide a link to the Creative Commons licence, and indicate if changes were made. The images or other third party material in this article are included in the article's Creative Commons licence, unless indicated otherwise in a credit line to the material. If material is not included in the article's Creative Commons licence and your intended use is not permitted by statutory regulation or exceeds the permitted use, you will need to obtain permission directly from the copyright holder. To view a copy of this licence, visit http://creativecommons.org/licenses/by/4.0/. 
typical asynchronous discussion facilitated by an online forum, messages are threaded in themes or topics, meaning that a series of messages are visually posted in a line or tree shape, enabling readers to easily follow the conversation flow and reply accordingly (Hew \& Cheung, 2012). Asynchronous online forum has been widely used in educational settings to support instructional purposes (Hara, Bonk, \& Angeli, 2000). However, scholars also found certain constraints about threaded forums. For example, Thomas (2002) pointed out that threaded asynchronous forum may not necessarily promote interactive conversations as students found it hard to understand how previous posts were interrelated due to the non-linear branching structure of asynchronous discussion. Most students tend to engage in "poorly interrelated monologues" (p. 351) rather than interactive conversations. Further, in a typical threaded asynchronous forum, participants are often involved in text-only interactions, so there is a lack of emotional expressions (Gao et al., 2013).

The advent of mobile communication technologies has significantly changed the way students interact. Statistics show that US adults are spending twice the amount of time per day with mobile messaging apps in 2019, compared to that of 2015 (eMarketer, 2019a). WhatsApp, accessed by 1.5 billion users, was the leading MIM app worldwide, followed by Facebook Messenger (1.3 billion) and WeChat ( 1 billion). It is projected that 2.48 billion people worldwide will communicate via messaging apps in 2021 (eMarketer, 2019b). MIM has surpassed voice calls, emails, and even face-to-face communication, to become the most popular means for young people to communicate (Lenhart, Purcell, Smith, \& Zickuhr, 2010).

Despite its unprecedented popularity, MIM remains the least explored learning tool (Rambe \& Bere, 2013). Previous studies have shown that MIM can advance students' learning by supporting social presence (e.g., Akcaoglu \& Lee, 2018; Ogara, Koh, \& Prybutok, 2014). However, questions remain over how social presence is projected in a MIM-supported learning context. Moreover, we do not know to what extent MIM can facilitate social presence compared to other technologies, as no comparative study has been done on this topic of interest. Understanding which tool can better promote social presence will help an online or blended learning instructor select the right tool to build connections among the students and enhance their learning experience.

To address the gaps, a mixed-method two-stage study was conducted in a higher education setting. Stage 1 was an exploratory study to understand how social presence was projected in an MIM environment. Stage 2 compared the levels of social presence afforded by the quasi-synchronous MIM platform with those generated in an asynchronous threaded discussion forum and surveyed possible explanations to the differences. The online discussion forum was chosen because it is a commonly utilized technological tool to facilitate online discussions in higher education and has been widely examined in relation to social presence (e.g., Chiecher \& Donolo, 2013; Kovanović et al., 2018; Kožuh et al., 2015). Using the validated instrument by Rourke, Anderson, Garrison, and Archer (2001), we measured the levels of social presence in three dimensions, namely the affective, interactive, and cohesive responses. In the next section, we review the theoretical background and previous related studies and present the conceptual framework. 


\section{Literature review}

\section{Social presence: definition and significance}

The notion of social presence was first introduced to evaluate the capabilities of certain mediums, whether they transmitted sufficient information and affected the salience of communication (Short, Williams, \& Christie, 1976). It is based on social psychology theories of interpersonal communication and related to the notions of intimacy and immediacy (Biocca, Harms, \& Burgoon, 2003; Rice, 1993). Specifically, immediacy is defined as the "directness and intensity of interaction" (Mehrabian, 1967) and can be realized both verbally and non-verbally, while intimacy is closely related to human relationships and is manifested through factors like physical distance, eye contact, and facial expressions (Argyle \& Dean, 1965). Gunawardena and Zittle (1997) regarded a medium as being more conducive to developing intimacy if it was capable of conveying more non-verbal cues. For example, a video may facilitate more social presence than a text message because it is capable of transmitting non-verbal cues such as body movements.

In a survey of a distance education program, Gunawardena (1995) found that the students' perception of the media characteristics, rather than the medium alone, was related to social presence. In line with this, Garrison, Anderson, and Archer (1999) described social presence as "the ability of participants... to project themselves socially and emotionally, as 'real' people (i.e., their full personality)" (p. 94). Therefore, researchers have contended that social presence is more than a mere feature of the medium; it can be influenced by an individual's perception and cultivated by non-media factors such as the communicative context, tasks, and purposes (Öztok \& Kehrwald, 2017).

Researchers have found that social presence is positively correlated with students' online participation frequency (Rourke et al., 2001), perception of learning (Gunawardena \& Zittle, 1997), and also reduces stress and the sense of loneliness (Whiteside, Dikkers, \& Lewis, 2014). In virtual environments where few visual cues are available, social presence is an important mediating variable in collaborative learning and critical discourse (Garrison, 2011). Garrison et al. (1999) explained that its primary importance is the "function as a support for cognitive presence, indirectly facilitating the process of critical thinking" (p. 89). In a recent meta-analysis, Richardson, Maeda, Lv, and Caskurlu (2017) concluded that social presence can influence student learning in terms of (1) participation and motivation, (2) satisfaction with the course and instructor, (3) course design, (4) intention and retention in online learning, (5) learning outcomes, and (6) critical thinking and higher-level learning. They also found moderately large positive correlations between social presence and student satisfaction $(r=0.56)$, and social presence and perceived learning $(r=0.51)$ (Richardson et al., 2017).

\section{Social presence and MIM use in education}

General MIM apps offer features such as private/group chats, emoticons/emoji?/ stickers, and the exchange of graphics, audio, and video messages. When a new message arrives, a push notification appears on the screen as an alert. This unique notification feature characterizes MIM as a platform of "quasi-synchronous" communication (Garcia \& Jacobs, 1999) because it enables users to initiate real-time chats immediately, as if they are talking in person, or to relay messages with a slight time lag if the 
correspondent is not immediately available. The mobility and flexibility of MIM have attracted people to use it frequently for social purposes. However, compared to other technologies, MIM remains to be the least explored learning tool despite its unprecedented popularity (Rambe \& Bere, 2013).

Previous studies have examined the relationship of using MIM for educational purposes and the levels of social presence demonstrated in the communication (Tang \& Hew, 2019; Kim, Lee, \& Kim, 2014). According to a survey of 239 college students, the MIM environment contributed to the manifestation of social presence, because of the better user experience, increased media richness, and greater social influence (the willingness to change behavior or beliefs) (Ogara et al., 2014). Researchers also identified specific social presence indicators by analyzing the MIM interactive content, such as the disclosure of personal details (Bouhnik \& Deshen, 2014), salutations (Miller, 2016), expression of compliments (Smit \& Goede, 2013), use of humor (Robinson et al., 2015), and expression of affect (Wang, Fang, Han, \& Chen, 2016). Wang et al. (2016) used MIM to facilitate language practices in an English course, and they reported that the two most frequently used features for expressing affect were emoticons (72\%) and photos (21\%), with the most frequently used emoticons being smiling faces and thumbs-up. However, these studies that examined MIM and social presence are largely descriptive or correlational. Descriptive studies did not examine the extent to which and in what manner social presence was facilitated.

Several researchers have posited that MIM may be superior to other online tools in projecting social presence (Rambe \& Bere, 2013; Robinson et al., 2015), but no empirical comparative studies have been done to verify this proposition. Previous studies compared different learning environments in supporting social presence, such as synchronous audio, the asynchronous text-based conferencing, and the asynchronous video feedback. For example, LaPointe, Greysen, and Barrett (2004) found that using synchronous audio in language learning promoted social presence through the increased use of emoticons and the exchange of intimate information. In contrast, King and Ellis (2009) reported no significant difference in the levels of social presence generated in voice-based and text-based asynchronous computer conferences. Thomas, West, and Borup (2017) found very minimal differences in the numbers of social presence indicators in text and video feedback. Traphagan et al. (2010) found similar levels of social presence elements in a 3D Second Life virtual world and a text-chat debate. However, none of them paid attention to the quasi-synchronous MIM environment. Can MIM better facilitate social presence than other technological platforms? The answer is still unknown.

In sum, MIM remains one of the least examined technological tools to support learning, and our understanding towards how social presence is manifested in an MIM environment is still limited. In addition, the few studies examined MIM and social presence are mostly descriptive in nature. By far, no studies have specifically compared the empirical differences between MIM and other technologies in relation to their capacity to promote social presence. To bridge these gaps, this study is guided by the following three research questions.

RQ1: How is social presence demonstrated in MIM-enabled class online interactions? (Study 1). 
RQ2: Are there any differences in the levels of social presence manifested in MIMenabled quasi-synchronous interaction and forum-enabled asynchronous interaction? (Study 2).

RQ3: If differences exist, what are the possible contributing factors? (Study 2).

\section{Conceptual framework}

To measure online social presence, Rourke et al. (2001) proposed an analytical framework with three categories, namely the affective, interactive, and cohesive responses. Multiple indicators were generated and assigned to the categories through an iterative process. In this framework, affective responses characterize the expression of emotion, feelings, and mood; interactive responses show evidence that people are connected and responding; and cohesive responses maintain a sense of group commitment (Rourke et al., 2001). It has been the most cited framework in the literature to measure social presence in virtual environments using the content analysis method (Thomas et al., 2017).

Researchers have modified the original framework to suit various research contexts accordingly, including video feedback (Thomas et al., 2017), video conference (King \& Ellis, 2009), and MIM (Wang et al., 2016). We referred to relevant studies and made the following adaptations to address the specialty in this study (see Table 1).

(1) Added "using emoji? and stickers" to the indicator of "expression of emotions," following Wang et al. (2016). Emoticons, emoji?, and stickers are frequently used to "express emotion and enhance a sense of trust and create a friendly atmosphere" (Wang et al., 2016, p. 26).

(2) Renamed the indicator "continue a thread" as "continue an idea" because there are no threads in MIM communication. The software features were specified as "reply" in the forum and the "@” function in MIM.

(3) Added "providing support" as an indicator of cohesive communication, following Thomas et al. (2017). This indicator is considered to contribute to the development of a cohesive learning community in a context where the learners are separated by time and space.

(4) Removed the indicator of "quoting from others' messages" because this was not found in the MIM and online forum groups.

\section{Methodology}

Permission to conduct this study was granted by the university's Human Research Ethics Committee for Non-Clinical Faculties. All participants were aged above 18. Participants' signed consent forms were gathered before the data collection commenced.

\section{Research design}

To answer the research questions, we conducted a two-stage mixed-method study, as shown in Fig. 1. Stage 1 examined how social presence was displayed when students used MIM in course-related discussions. An exploratory descriptive study was carried out in class A, with a retrospective analysis of MIM messages. Stage 2 examined, first, whether MIM was superior in facilitating social presence to the online forum and, 
Table 1 Categories and indicators of social presence

\begin{tabular}{|c|c|c|c|}
\hline Categories & Indicators & Definition & Example from interactions \\
\hline \multirow[t]{3}{*}{ Affective } & Expression of emotions & $\begin{array}{l}\text { Conventional or unconventional } \\
\text { expressions of emotion, including } \\
\text { repetitious punctuation, } \\
\text { conspicuous capitalization, } \\
\text { emoticons, emoji?, and stickers }\end{array}$ & $\begin{array}{l}\text { "Hahahaha [ThumbsUp] so } \\
\text { this way does work." }\end{array}$ \\
\hline & Use of humor & $\begin{array}{l}\text { Teasing, cajoling, irony, } \\
\text { understatements, and sarcasm }\end{array}$ & $\begin{array}{l}\text { "Are you serious that your } \\
\text { parents will beat you? I will } \\
\text { tell your mom about that!" }\end{array}$ \\
\hline & Self-disclosure & $\begin{array}{l}\text { Presentation of details of life } \\
\text { outside class or expresses } \\
\text { vulnerability }\end{array}$ & $\begin{array}{l}\text { "I was working part time in } \\
\text { a center that was providing } \\
\text { corporate training." }\end{array}$ \\
\hline \multirow[t]{4}{*}{ Interactive } & Continue an idea & $\begin{array}{l}\text { Replying to a previous thread } \\
\text { rather than starting a new one, } \\
\text { using "Reply" in the forum and } \\
\text { "@" in MIM (software dependent) }\end{array}$ & $\begin{array}{l}\text { "@Sara (pseudo), Just got } \\
\text { an idea after reading your } \\
\text { reply." }\end{array}$ \\
\hline & Asking questions & $\begin{array}{l}\text { Asking questions of other } \\
\text { students or the moderator }\end{array}$ & $\begin{array}{l}\text { "Were you the only one } \\
\text { responsible for the course? }\end{array}$ \\
\hline & $\begin{array}{l}\text { Complimenting, expressing } \\
\text { appreciation }\end{array}$ & $\begin{array}{l}\text { Complimenting others or } \\
\text { contents of others' messages }\end{array}$ & "Your sharing is interesting!" \\
\hline & Expressing agreement & $\begin{array}{l}\text { Expressing agreement with } \\
\text { others or about the content } \\
\text { of others' messages }\end{array}$ & "I agree with you." \\
\hline \multirow[t]{4}{*}{ Cohesive } & Vocatives & $\begin{array}{l}\text { Addressing or referring to } \\
\text { participants by name }\end{array}$ & "Hi Michael, I agree with you. \\
\hline & $\begin{array}{l}\text { Addresses or refers to the } \\
\text { group using inclusive } \\
\text { pronouns }\end{array}$ & $\begin{array}{l}\text { Addressing the group as we, } \\
\text { us, our, and group or other } \\
\text { implicit ways }\end{array}$ & $\begin{array}{l}\text { "I was really happy to meet } \\
\text { everyone last evening." }\end{array}$ \\
\hline & Phatics & $\begin{array}{l}\text { Communication that serves } \\
\text { a social function: greetings } \\
\text { and closures }\end{array}$ & $\begin{array}{l}\text { "I was really happy to meet } \\
\text { everyone last evening." }\end{array}$ \\
\hline & Providing support & $\begin{array}{l}\text { Support provided by either } \\
\text { students or the instructor } \\
\text { to others in the group }\end{array}$ & $\begin{array}{l}\text { "This research finding } \\
\text { provides a hint to your } \\
\text { question." }\end{array}$ \\
\hline
\end{tabular}

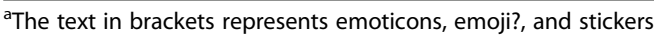

\begin{tabular}{|c|c|c|c|}
\hline Aim & Stage & Class & Environments \\
\hline $\begin{array}{l}\text { To examine how MIM } \\
\text { supported social } \\
\text { presence development. }\end{array}$ & $\begin{array}{l}\text { Stage One: } \\
\text { Descriptive }\end{array}$ & A & Quasi-synchronous (MIM) \\
\hline To compare the & & A & Quasi-synchronous (MIM) \\
\hline and Forum discussions, & & B & Asynchronous (forum) \\
\hline
\end{tabular}

Fig. 1 Overview of the two-stage research 
second, if differences exist, what factors had possibly contributed to the differences. This historical cohort control-experimental study was conducted in groups A and B to compare the levels of affective, interactive, and cohesive social presence in the two groups using MIM and forum, respectively.

\section{Participants and procedure}

This study was conducted in a large public Asian university with two classes taking the same postgraduate course, about the principles and strategies to engage adult learners. The course was taught in a flipped way in a blended environment. Content videos and online discussion topics were disseminated before each class session and the instructorfacilitated in-class activities and assigned reflective tasks after each session. A sample online discussion task was "Talk about the most important things for designing an adult course." The pre- and post-class online discussions were performed on the designated platforms. Students understood that their participation in the out-of-class activities was voluntary and would not be counted towards their grades. They were also informed that the instructor would not participate, unless they specifically sought help from him.

Class A was enrolled in the 2016 fall semester, composed of 26 graduate students (23 females and 3 males) in their 20s or 30s. All students were from mainland China and Hong Kong. Seven students were part-timers, and the rest were full-time students. The part-time students were school teachers who were interested in technologies or school technology professionals. Students conducted online discussions using a WeChat group. WeChat is one of the most popular MIM applications in Asia, especially in China, with about 1 billion active users (eMarketer, 2019b). It is equipped with all the typical MIM functions. Students joined the group discussion by scanning a Quick Response $(\mathrm{QR})$ code in the first week. All students had the application already installed on their smartphones before coming to the class. No one encountered any technical difficulties. Figure 2 shows the WeChat interface and its main functions.

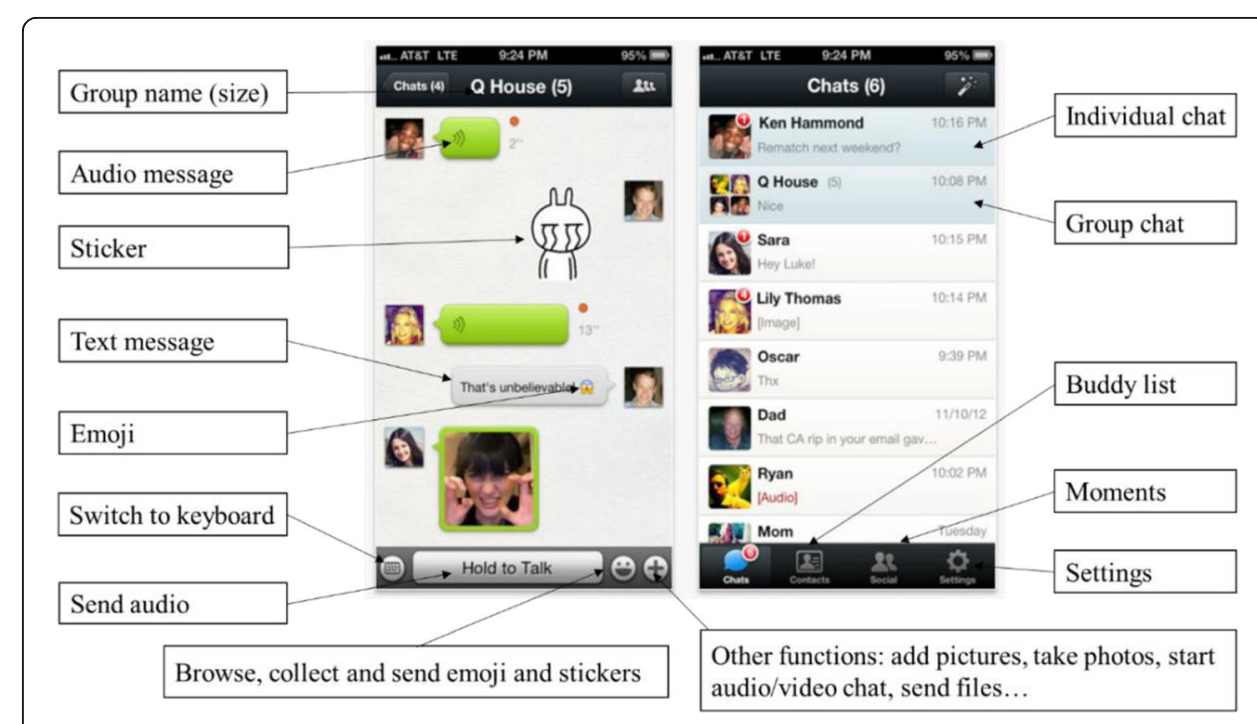

Fig. 2 WeChat interface and main functions 
Class B was in the 2017 spring semester, taught by the same instructor with the same content knowledge, resources, and activities. Among the 29 students involved (21 females and 8 males), one was from Thailand, and the rest were from mainland China and Hong Kong. All students were graduate students or young professionals in their $20 \mathrm{~s}$ or 30s. Five were studying part-time, and 24 were full-time students. Class B performed the same pre- and post-class online discussions on the online forum of Moodle, the learning management system used on campus. All students were familiar with how to use Moodle. No one encountered any technical difficulties.

\section{Data collection and analysis}

Data were collected from two main resources: online interactive records and student interviews. We retrieved the interaction records from the two groups and analyzed them with the content analysis method (Holsti, 1969). Content analysis is a generic name for a variety of textual analyses, which typically involves comparing, contrasting, and categorizing a set of data (Schwandt, 1997). This method has been adopted widely to analyze the quality of online interaction and make valid inferences from text (Anderson, Rourke, Garrison, \& Archer, 2001). As indicated, an a priori coding scheme by Rourke et al. (2001) was adopted to guide our analysis of student social presence levels in online communication. This analytical framework categorizes three dimensions of online social presence: affective responses, interactive responses, and cohesive responses. Because Rourke et al. (2001) analyzed asynchronous text-based conferencing communication, we made several modifications based on previous research (e.g., Thomas et al., 2017; Wang et al., 2016) to operationalize this framework in the context of threaded online forum and MIM discussions. Table 1 shows the adapted coding framework. The unit of analysis adopted in this study was the thematic unit, rather than the entire message, following Merriam's (2001) recommendation that meaning should be the main focus of communication.

Two independent researchers coded the data. The initial percentage of agreement was calculated as $90 \%$, and all disagreements were resolved through discussions. To identify possible contributing factors of the differences between using the two platforms, we conducted follow-up interviews with eight voluntary students. The interview records were transcribed verbatim and analyzed with the content analysis method. Specifically, inductive content analysis was adopted to identify and categorize the themes from interviews. No preconceived categories were employed. Rather, we allowed the topics to emerge from the data and successively refined the operationalization of the categories with iterative coding (Lincoln \& Guba, 1985).

For stage 2 study, simply counting the frequency of each indicator would not provide a fair comparison and represent the real picture, due to the effect of the varying message lengths. For example, if two messages have the same amount of indicators, but one contains more words than the other, it would be unfair to say these two messages represent the same level of social presence. To address this problem, we followed King and Ellis' (2009) procedure and compared the social presence density (SPD) score of each message: the sum of the raw number of indicators was divided by the total number of words and multiplied by 1000. For example, if one 100-word message contained 3 affective indicators and 2 cohesive indicators, we calculated the affective SPD as 3/ $100 \times 1000=30$ and the cohesive SPD as $2 / 100 \times 1000=20$. We regarded one 
emoticon/emoji/sticker as one word. This step enabled us to represent the frequency of indicators for every 1000 words of text and therefore eliminate the influence of message length. Mann-Whitney $U$ tests were conducted because a normality test indicated the data significantly deviated from a normal distribution. SPSS 22 was used to perform the analysis. Significance was accepted at the level of $p<.05$.

\section{Results}

Social presence demonstrated in MIM-enabled class online interactions

In stage 1 , we collected 418 records from group A and identified 753 social presence indicators. Figure 3 displays the frequency of each indicator and the total of each category. The results show that interactive responses made up the largest portion of the three dimensions. The top individual indicators were "expression of emotions," "addressing or referring to the group using inclusive pronouns," "continuing an idea," and "phatics."

\section{Differences in social presence levels between MIM-enabled and forum-enabled interactions}

In stage 2, we collected 418 postings from group A (MIM) and 169 from group B (forum). Group A posted over twice as many messages as group B. Table 2 displays the calculated SPD scores of each message and the average density (sum of density divided by the number of messages). MIM outperformed forum in the majority of indicators in both the total frequency and the average density per message, except the total frequency of the indicators "vocatives" and "addressing or referring to the group using inclusive pronouns," and the average density of "vocatives."

The SPDs were compared to provide more detailed insights about the specific ways in which MIM differed from the forum in facilitating social presence (Table 3). The results showed significant differences between the two groups in terms of (a)

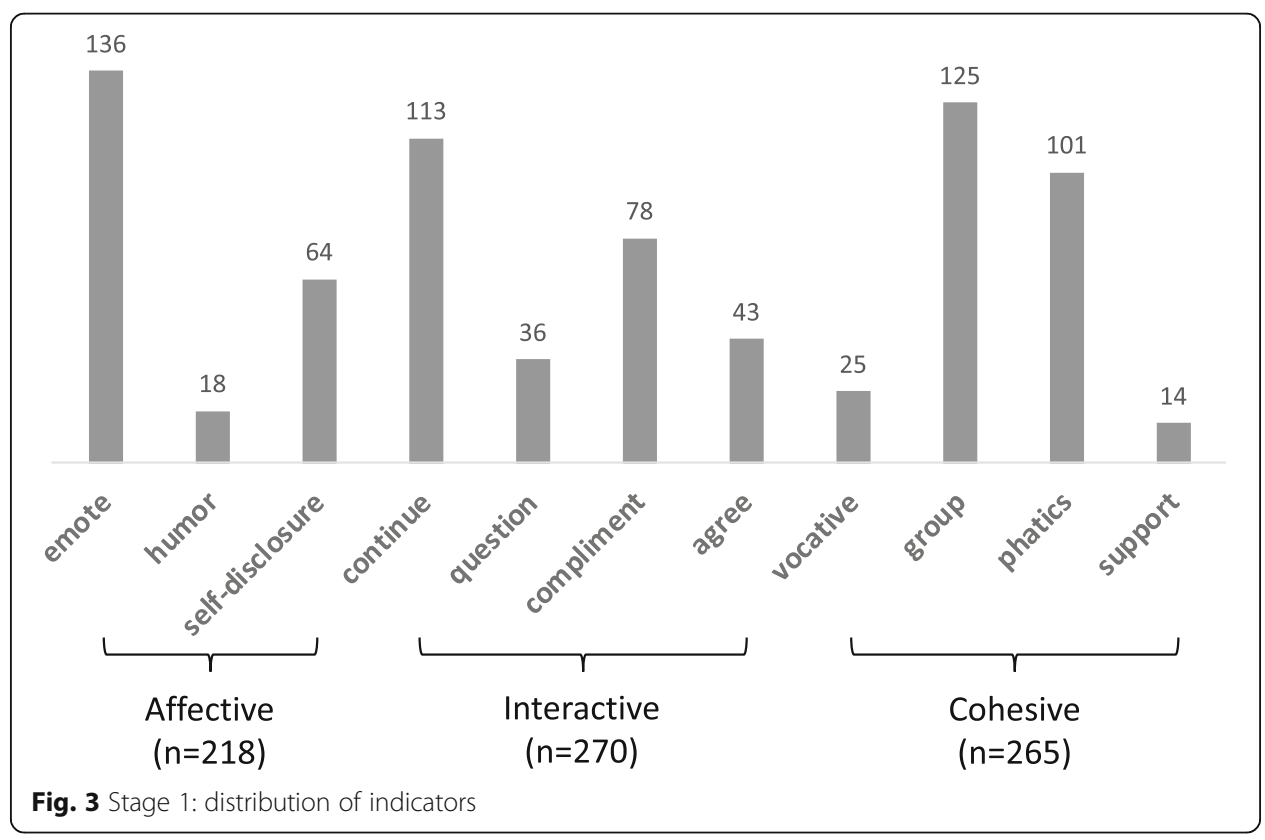


Table 2 Stage 2: Frequencies and densities of indicators

\begin{tabular}{|c|c|c|c|c|c|}
\hline \multirow[t]{2}{*}{ Dimensions } & \multirow[t]{2}{*}{ Indicators } & \multicolumn{2}{|c|}{ Total frequency } & \multicolumn{2}{|c|}{ Average density } \\
\hline & & MIM & Forum & MIM & Forum \\
\hline \multirow[t]{4}{*}{ Affective } & Expression of emotions & 136 & 12 & 62 & 5 \\
\hline & Use of humor & 18 & 3 & 7 & 2 \\
\hline & Self-disclosure & 64 & 33 & 4 & 2 \\
\hline & Total & 218 & 48 & 73 & 9 \\
\hline \multirow[t]{5}{*}{ Interactive } & Continuing an idea & 113 & 47 & 18 & 10 \\
\hline & Asking questions & 36 & 12 & 4 & 2.8 \\
\hline & Complimenting, expressing appreciation & 78 & 25 & 12 & 4.5 \\
\hline & Expressing agreement & 43 & 36 & 5 & 3.5 \\
\hline & Total & 270 & 120 & 39 & 21 \\
\hline \multirow[t]{5}{*}{ Cohesive } & Vocatives & 25 & 32 & 2 & 3 \\
\hline & $\begin{array}{l}\text { Addressing or referring to the group using } \\
\text { inclusive pronouns }\end{array}$ & 125 & 129 & 8 & 7 \\
\hline & Phatics & 101 & 6 & 16 & 1 \\
\hline & Providing support & 14 & 0 & 8 & 0 \\
\hline & Total & 265 & 167 & 34 & 11 \\
\hline
\end{tabular}

affective-expression of emotions $(U=29,372, p<0.001)$; (b) cohesive-vocatives $(U=$ $31,777, p<0.001)$; (c) cohesive-phatics $(U=29,223, p<0.001)$; and (d) cohesive-providing support $(U=34,223, p=0.021)$. The results indicated a borderline significant difference in the interactive dimension: expressing agreement $(U=33,203, p=0.046)$. No significant differences were found among other indicators.

\section{Possible contributing factors}

Students' interviews were analyzed to seek possible answers to the differences in social presence levels. Four main possible factors emerged as to why MIM is unique

Table 3 Comparison of social presence by indicators

\begin{tabular}{llllll}
\hline Dimensions & Indicators & \multicolumn{3}{l}{ Significance of difference (MIM vs. forum) } & \\
\cline { 3 - 6 } & & Mann-Whitney $U$ & Wilcoxon W & $Z$ & Asymp. Sig. (2-tailed) \\
\hline Affective & Expression of emotions & 29,373 & 43,738 & -4.75 & $<0.001^{*}$ \\
& Use of humor & 34,422 & 48,787 & -1.50 & 0.133 \\
& Self-disclosure & 34,486 & 122,057 & -0.71 & 0.480 \\
\multirow{4}{*}{ Interactive } & Continuing an idea & 34,368 & 48,733 & -0.66 & 0.509 \\
& Asking questions & 34,983 & 49,348 & -0.41 & 0.684 \\
& Complimenting, expressing & 33,461 & 47,826 & -1.60 & 0.109 \\
& appreciation & & & & \\
\multirow{2}{*}{ Cohesive } & Expressing agreement & 33,203 & 120,774 & -2.00 & $0.046^{*}$ \\
& Vocatives & 31,777 & 119,348 & -3.90 & $<0.001^{*}$ \\
& Addressing the group with & 33,118 & 120,689 & -1.60 & 0.110 \\
& inclusive pronouns & & & & \\
& Phatics & 29,223 & 43,588 & -5.16 & $<0.001^{*}$ \\
& Providing support & 34,223 & 48,588 & -2.32 & $0.021^{*}$ \\
\hline$p<0.05$ & & & & &
\end{tabular}


(compared to forum) and how these unique features help facilitate the expressions of emotion, agreement, phatics, and providing support. These four factors are (a) ease of use of non-verbal cues such as emoji? and stickers, (b) location-free digital interaction, (c) presence awareness, and (d) multimodality.

First, the convenient use of non-verbal cues, especially emoji? and stickers, helped foster a higher level of affective social presence (expression of emotions) in MIM. Popular MIM apps such as WeChat provide a series of built-in emoticons and emoji? that the users can send with a single click. WeChat even allows users to design and launch their own sticker sets, which add an element of individuality and fun. As one student commented, "it is so much easier and more fun to express feelings with sending a sticker than describing it verbally in a long sentence." Sharing emotions has a stronger impact on perceived intimacy than factual information sharing (Laurenceau, Barrett, \& Rovine, 2005). Compared to MIM, online forums lack a convenient support for expressing emotions in this way. One criticism of asynchronous textual communication is that users have to describe their feelings verbatim in multiple messages to compensate for the lack of non-verbal cues (Walther, 1992).

Second, the location-free digital interactions of MIM provided a more spontaneous and informal mode of communication than the online forum ( $\mathrm{Tu}$, McIsaac, SujoMontes, \& Armfield, 2013). Students usually accessed the online forum via their desktops and had to click multiple links before using the function. Online forum was less mobile-friendly and seen as more "work" related. One student stated, "(with WeChat) I can check the information and reply to my friends, when I am waiting for the elevator or standing in the queue for a Subway sandwich." In addition, students generally stated that they felt more comfortable expressing affect in WeChat, whereas the online forum demanded more formal expressions. "In the relaxed atmosphere (of WeChat), I can share ideas even though they are not quite properly formed." In comparison, Moodle is "formal... anything is work-related. Casual talk is inappropriate." Another student remarked that writing on the forum "feels like taking an exam and answering test questions. I normally spent more than 20 minutes to write one message. They are expected to be grammatically correct and in complete sentences."

In addition, the relaxed WeChat environment fostered more cohesive social presence (providing support). It enabled potential help providers to respond with less time and effort. One student commented, "If somebody asks for help on forum, I will have to carefully make sure everything is grammatically correct. But on WeChat, I can say what comes into my mind without without worrying about the grammar. It takes more time to put the ideas into words on forum." In fact, no students asked for help via forum, and in the interviews, no students stated that they would use the online forum to communicate if in need of assistance.

Third, the presence awareness feature of MIM may also help explain why a higher level of "cohesive social presence: providing support" was demonstrated on WeChat. When a new message arrives, the push notification will alert the users to start conversing with the least time lag. It also provides users with a continuous awareness of others' availability on the app to encourage support provision. One student described "classmates as being more approachable ... and the WeChat alert will increase the chance of being answered, when you need help." 
Fourth, the capture function of smartphones with digital cameras enables users to send multimodal messages (e.g., photos and videos) easily. This contributes to an improved sense of connection and promotes phatic communication, which is described as messages that establish and maintain social bonds with interlocutors (Kofoed \& Larsen, 2016). For example, in the MIM group, a student took a photo of herself sitting on a beach to share her vacation. When asked how other students felt when they saw this picture, one student noted, "It's lively and vivid, like I can see her in person ... It is interesting to see where she is traveling to and what she is experiencing." According to Bentley and Metcalf (2009), posting pictures enables other people to initiate phatic communication because it allows them to feel as if they are connected to the events that are occurring in other places. Phatic communications function like linguistic signals in maintaining connections with other people (Makice, 2009), which "are very meaningful, and imply the recognition, intimacy and sociability in which a strong sense of community is founded" (Miller, 2008, p. 395). This in turn helps strengthen the cohesive social presence.

\section{Discussion and conclusion}

In this two-stage study, we explored how social presence was displayed in a MIMfacilitated environment and compared the social presence levels manifested in the MIM group to those in the online forum group. The results show that, first, MIM enabled students to demonstrate social presence through affective, interactive, and cohesive responses. Particularly, students seemed to be most comfortable to use MIM to express emotions, address groups, and continue a discussion. Second, compared to the online forum, MIM is particularly suited to promoting the expression of emotions, agreement, phatics, and providing support. Students using the online forum exhibited significantly more vocatives (cohesive) than those using MIM. From students' interviews, four attributes were reported that might have contributed to the differences, including (a) the ease of use of non-verbal cues such as emoji? and stickers, (b) locationfree digital interaction, (c) presence awareness, and (d) multimodality. In the following paragraphs, we present some concerns voiced by students in the interviews and discuss the implications of the current study.

\section{Concerns of MIM-facilitated communications}

The major concern of the interviewees is about the manner of managing mobile communications. Specifically, some of the students found the presence awareness to be stressful because they were being alerted all the time by the notifications and they sometimes felt obliged to reply immediately. However, if they muted the notifications or chose not to reply, they would lose the interaction or may even undermine their relationships. One student stated, "The notification on my screen makes me feel a little bit anxious. We will immediately check the message as soon as we see the pop-up window. It has become a habit for most of us." Another student stated that, "Even if you can choose to reply later, this thought of replying will haunt you. It keeps coming to your mind until you actually send out the reply. I would be distracted from what I am doing and cannot stay focused." This negative impact of presence awareness is also mentioned in the literature. Students, especially those with families, prefer keeping life 
and work separate and do not want to receive school-related messages outside of instructional hours (Tang \& Hew, 2017).

In addition, the chronological display of MIM messages prevents users from easily orientating themselves towards the most relevant messages. In other words, MIM messages are not organized in threads, and students may easily get lost in volumes of information. One student expressed, "it is sometimes frustrating if you cannot find the right post because the messages just flood in, especially when there are many people in a group and they talk at the same time." This chronicle display of messages may also explain why the MIM group exhibited significantly fewer instances of the "cohesive social presence: vocatives" indicator. Users tended to reply to the immediate message as in face-to-face situations, in which the two parties normally carry on a conversation without needing to specifically address the other person by name. This point was supported by a student who stated that, "You do not need to explicitly write the person's name in your WeChat message."

\section{Implications for practice}

Our findings suggest that MIM promotes a greater online social presence among students or at the very least, has no adverse effect compared to a threaded online forum. The instructors of fully online or blended learning classes can thus choose to use MIM technologies such as WeChat or WhatsApp to facilitate student discussion of course-related materials. However, WhatsApp requires users to add contacts with phone numbers, which may be undesirable for students who wish to keep their numbers private. In contrast, WeChat allows users to add contacts using the WeChat ID or by simply scanning a user's QR code. Because no phone numbers are required, WeChat might be more attractive to students who do not wish to share their private mobile numbers.

Second, several students remarked that the push notification function can sometimes create undesirable stress and place pressure on the user to respond immediately. One strategy to address this issue is to establish a timeline for responding to mobile communications, such as to allow "24 hours response time during weekdays and 1-2 days for the weekend" (Tu et al., 2013, p. 93). The instructor may negotiate with students and modify this guideline as needed according to their feedback. Overall, it is important to establish common protocols for communication in order to avoid potential tension among users.

\section{Implications for future research}

This study has broadened our theoretical understanding of the social presence generation in an MIM environment. To further advance relevant research, we think the following five issues are worth future investigation.

First, previous studies seemed to have reached a consensus that students with higher levels of social presence would perceive higher levels of learning and scored higher in assessments in blended or completely online environments (e.g., Picciano, 2002; Richardson et al., 2017; Richardson \& Swan, 2003; So \& Brush, 2008). Recently, Sun, Lin, Wu, Zhou, and Luo (2018) compared the interaction types between using an online discussion forum and an MIM app and found that students were more 
involved in social interactions when using MIM but more in knowledge construction when using forum. However, this study only presented descriptive results and adopted a broad categorization of interaction types (social interaction and knowledge construction), which did not empirically examine in-depth the levels of thinking. As a result, no study by far has been done to investigate whether the improved level of social presence in MIM-supported communication will lead to higher levels of learning. Understanding how different technologies can impact social presence and learning is a meaningful direction for researchers and educators to explore in the future.

Second, we do not really know how different students demonstrate and experience social presence in an MIM environment. For example, does gender mediate students' social presence? In both stages of the present study, most of the research participants were female (e.g., in stage 1, 20 of the 22 participants were females, and in stage 2, 23 of the 26 students were females). There is a possibility that different gender may affect different levels of social presence. Furthermore, how do different personality traits affect students' social presence? Do students from different cultural backgrounds demonstrate different levels of social presence? Future research can examine these issues.

Third, how does using different discussion strategies influence social presence? Although it has been suggested that online discussion strategies may influence the levels of social presence, few studies have examined this issue (Saude et al., 2012). The discussion strategy in our study may best be considered as an open-ended reflective discussion with an initial prompt. Both the MIM and online forum groups used the same discussion strategy to control for task equivalence. However, the question remains as to whether the use of other discussion strategies, such as debate and role-play, would have affected the levels of social presence in online interactions.

Fourth, future research should examine whether the use of emoticons, emoji?, and stickers have different effects on students' social presence in an MIM environment. Emoticons are a group of keyboard characters, such as :-) to represent facial expressions, whereas emoji? are small images (e.g., ¿) to express the users' emotions. Stickers are customized pictures that are exclusive to particular mobile applications, which can be textual, pictorial, or a combination of both, and can also be static or dynamic. For example, the following textual-pictorial-dynamic sticker shows an animal moves its head up and down and screams, with the expression "ahh" printed above the animated picture textual-pictorial and dynamic stickers demonstrate a stronger social presence than those who use static images or emoticons and emoji?

Fifth, we urge future studies on students' social presence to be longitudinal, in which "information is repeatedly collected overtime on the same sample of individuals" (Goldstein, 1968, p. 95). Extant studies on social presence within the context of MIM have only lasted about one semester. Short-term studies with new technologies may be hindered by the novelty effect due to the tendency of users to pay increased interest (Clark, 1983). Longitudinal studies of at least 1 year's duration need to be conducted so that educators can evaluate the long-term effects of using MIM on social presence. 
Acknowledgements

We thank teachers and students who have made valuable contributions to this study.

\section{Authors' contributions}

YT conceived and designed the study, collected the data, performed the data analysis, drafted the manuscript, and critically revised the paper. KFH conceived and designed the study and critically revised the paper. Both authors read and approved the final manuscript.

\section{Funding}

The authors received no specific funding for this work.

\section{Availability of data and materials}

The original data are protected as confidential under the university IRB guidelines. Other materials are available upon request.

\section{Competing interests}

The authors declare that they have no competing interests.

\section{Author details}

${ }^{1} S c h o o l$ of Informatics, Computing, and Engineering, Indiana University, Myles Brand Hall 210, 901 E 10th Street, Bloomington, IN 47408, USA. ${ }^{2}$ Faculty of Education, University of Hong Kong, Runme Shaw 112, Pokfulam, Hong Kong.

\section{Received: 3 September 2019 Accepted: 27 February 2020}

\section{Published online: 16 April 2020}

\section{References}

Akcaoglu, M., \& Lee, E. (2018). Using Facebook groups to support social presence in online learning. Distance Education, 39(3), 334-352. https://doi.org/10.1080/01587919.2018.1476842

Anderson, T., Rourke, L., Garrison, D. R., \& Archer, W. (2001). Assessing teaching presence in a computer conferencing context. Journal of Asynchronous Learning Networks, 5(2), 1-17 Retrieved from https://olj.onlinelearningconsortium.org/index.php/ olj/article/view/1875/706.

Argyle, M., \& Dean, J. (1965). Eye-contact, distance and affiliation. Sociometry, 28(3), 289. https://doi.org/10.2307/2786027.

Tang, Y., \& Hew, K. F. (2017). Is mobile instant messaging (MIM) useful in education? Examining its technological, pedagogical, and social affordances. Educational Research Review, 21(2017), 85-104. https://doi.org/10.1016/j.edurev. 2017.05.001.

Tang, Y., \& Hew, K. F. (2019). Examining the utility and usability of mobile instant messaging in a graduate-level course: A usefulness theoretical perspective. Australasian Journal of Educational Technology, 35(4), 128-143. https://doi.org/10. 14742/ajet.4571.

Bentley, F., \& Metcalf, C. J. (2009). The use of mobile social presence. IEEE Pervasive Computing, 8(4), 35-41. https://doi.org/10. 1109/mprv.2009.83.

Biocca, F., Harms, C., \& Burgoon, J. K. (2003). Toward a more robust theory and measure of social presence: Review and suggested criteria. Presence Teleoperators and Virtual Environments, 12(5), 456-480. https://doi.org/10.1162/ 105474603322761270

Bouhnik, D., \& Deshen, M. (2014). WhatsApp goes to school: Mobile instant messaging between teachers and students. Journal of Information Technology Education: Research, 13(1), 217-231. https://doi.org/10.28945/2051.

Chiecher, A. C., \& Donolo, D. S. (2013). Virtual dialogues and exchanges: The social and cognitive dimensions of interactions among students. International Journal of Educational Technology in Higher Education, 10(2), 285-300. https://doi.org/10. 7238/rusc.v10i2.1534.

Clark, R. E. (1983). Reconsidering research on learning from media. Review of Educational Research, 53(4), 445-459. https://doi org/10.2307/1170217.

eMarketer. (2019a). Average time spent per day with mobile messaging apps by adults in the United States 2015 to 2019. In Statista - The Statistics Portal. Retrieved from https:/www.statista.com/statistics/266925/adult-daily-mobile-messagingapp-engagement-usa/

eMarketer. (2019b). Number of mobile phone messaging app users worldwide from 2016 to 2021 (in billions). In Statista The Statistics Portal. Retrieved from https://www.statista.com/statistics/483255/number-of-mobile-messaging-usersworldwide/

Gao, F., Zhang, T., \& Franklin, T. (2013). Designing asynchronous online discussion environments: Recent progress and possible future directions. British Journal of Educational Technology, 44(3), 469-483. https://doi.org/10.1111/j.1467-8535. 2012.01330.x.

Garcia, A. C., \& Jacobs, J. B. (1999). The eyes of the beholder: Understanding the turn-taking system in quasi-synchronous computer-mediated communication. Research on Lanquage and Social Interaction, 32(4), 337-367. https://doi.org/10.1207/ S15327973rls3204_2

Garrison, D. (2011). E-learning in the 21st century: A framework for research and practice. New York: Routledge. https://doi.org/ 10.4324/9780203838761.

Garrison, D. R., Anderson, T., \& Archer, W. (1999). Critical inquiry in a text-based environment: Computer conferencing in higher education. The Internet and Higher Education, 2(2), 87-105. https://doi.org/10.1016/s1096-7516(00)00016-6.

Gerosa, M. A., Filippo, D., Pimentel, M., Fuks, H., \& Lucena, C. J. P. (2010). Is the unfolding of the group discussion off-pattern? Improving coordination support in educational forums using mobile devices. Computers \& Education, 54, 528-544. https://doi.org/10.1016/j.compedu.2009.09.004.

Goldstein, H. (1968). Longitudinal studies and the measurement of change. Journal of the Royal Statistical Society, 18(2), 93117. https://doi.org/10.2307/2986775. 
Gunawardena, C. N. (1995). Social presence theory and implications for interaction and collaborative learning in computer conferences. International Journal of Educational Telecommunications, 1(2), 147-166 Retrieved from https://www. learntechlib.org/p/15156/.

Gunawardena, C. N., \& Zittle, F. J. (1997). Social presence as a predictor of satisfaction within a computer-mediated conferencing environment. American Journal of Distance Education, 11(3), 8-26. https://doi.org/10.1080/ 08923649709526970.

Hara, N. M., Bonk, C. J. M., \& Angeli, C. M. (2000). Content analysis of online discussion in an applied educational psychology course. Instructional Science, 28, 115-152 Retrieved from https://link.springer.com/article/10.1023/A:1003764722829.

Hew, K. F., \& Cheung, W. S. (2012). Student participation in online discussions: Challenges, solutions, and future research. New York: Springer Science \& Business Media.

Holsti, R. (1969). Content analysis for the social sciences and humanities. Reading: Addison-Wesley. https://doi.org/10.2307/ 2093233.

Kim, H., Lee, M., \& Kim, M. (2014). Effects of mobile instant messaging on collaborative learning processes and outcomes: The case of South Korea. Journal of Educational Technology \& Society, 17(2), 31-42 Retrieved from https://www.jstor.org/ stable/jeductechsoci.17.2.31.

King, K., \& Ellis, T. J. (2009). Comparison of social presence in voice-based and text-based asynchronous computer conferences. In The 42nd Hawaii International Conference on System Sciences, (pp. 1-10). https://doi.org/10.1109/hicss. 2009.119 .

Kofoed, J., \& Larsen, M. C. (2016). Photo-sharing practices among young people on social media. First Monday, 21(11) Retrieved from http://firstmonday.org/ojs/index.php/fm/article/view/6905/5648.

Kovanović, V., Joksimović, S., Poquet, O., Hennis, T., Čukić, I., de Vries, P., \& Gašević, D. (2018). Exploring communities of inquiry in massive open online courses. Computers \& Education, 119, 44-58. https://doi.org/10.1016/j.compedu.2017.11.010.

Kožuh, I., Jeremić, Z., Sarjaš, A., Lapuh Bele, J., Devedžić, V., \& Debevc, M. (2015). Social presence and interaction in learning environments: The effect on student success. Educational Technology \& Society, 18(1), 223-236 Retrieved from www.jstor. org/stable/jeductechsoci.18.1.223.

LaPointe, D. K., Greysen, K. R., \& Barrett, K. A. (2004). Speak2Me: Using synchronous audio for ESL teaching in Taiwan. International Review of Research in Open and Distance Learning, (1), 5 Retrieved from http://www.irrodl.org/index.php/ irrodl/article/view/166/386. Doi: https://doi.org/10.19173/irrodl.v5i1.166.

Laurenceau, J. P., Barrett, L. F., \& Rovine, M. J. (2005). The interpersonal process model of intimacy in marriage: A daily-diary and multilevel modeling approach. Journal of Family Psychology, 19(2), 314-323. https://doi.org/10.1037/0893-3200.19.2. 314.

Lenhart, A., Purcell, K., Smith, A., \& Zickuhr, K. (2010). Social media and mobile Internet use among teens and young adults. Retrieved from http://www.pewinternet.org/2010/02/03/social-media-and-young-adults/

Lincoln, Y. S., \& Guba, E. G. (1985). Naturalistic inquiry. Beverly Hills: Sage Publications.

Makice, K. (2009, April). Phatics and the design of community. CHI09 on Human Factors in Computing Systems (pp. 31333136). ACM. doi: https://doi.org/10.1145/1520340.1520445

Mehrabian, A. (1967). Orientation and behaviors and nonverbal attitude communication. Journal of Communication, 17, $324-$ 332. https://doi.org/10.1111/j.1460-2466.1967.tb01190.x.

Merriam, S. B. (2001). Qualitative research and case study applications in education. San Francisco: Jossey-Bass.

Miller, L. (2016). Collaborative script writing for a digital media project. Writing \& Pedagogy, 8(1), 215-228. https://doi.org/10 1558/wap.v8i1.27593.

Miller, V. (2008). New media, networking and phatic culture. Convergence, 14(4), 387-400. https://doi.org/10.1177/ 1354856508094659 .

Ogara, S. O., Koh, C. E., \& Prybutok, V. R. (2014). Investigating factors affecting social presence and user satisfaction with mobile instant messaging. Computers in Human Behavior, 36, 453-459. https://doi.org/10.1016/j.chb.2014.03.064.

Öztok, M., \& Kehrwald, B. A. (2017). Social presence reconsidered: Moving beyond, going back, or killing social presence. Distance Education, 38(2), 259-266. https://doi.org/10.1080/01587919.2017.1322456.

Picciano, A. G. (2002). Beyond student perceptions: Issues of interaction, presence, and performance in an online course Journal of Asynchronous Learning Networks, 6(1), 21-40. https://doi.org/10.24059/olj.v6i1.1870.

Rambe, P., \& Bere, A. (2013). Using mobile instant messaging to leverage learner participation and transform pedagogy at a South African University of Technology. British Journal of Educational Technology, 44(4), 544-561. https://doi.org/10.1111/ bjet.12057.

Rice, R. (1993). Media appropriateness; using social presence theory to compare traditional and new organizational media. Human Communication Research, 19, 451-484. https://doi.org/10.1111/j.1468-2958.1993.tb00309.x.

Richardson, J. C., Maeda, Y., LV, J., \& Caskurlu, S. (2017). Social presence in relation to students' satisfaction and learning in the online environment: A meta-analysis. Computers in Human Behavior, 71, 402-417. https://doi.org/10.1016/j.chb.2017.02.001.

Richardson, J. C., \& Swan, K. (2003). Examining social presence in online courses in relation to students' perceived learning and satisfaction. Journal of Asynchronous Learning Networks, 7(1), 68-88 Retrieved from https://olj. onlinelearningconsortium.org/index.php/olj/article/view/1864.

Robinson, L., Behi, O., Corcoran, A., Cowley, V., Cullinane, J., Martin, I., \& Tomkinson, D. (2015). Evaluation of WhatsApp for promoting social presence in a first-year undergraduate radiography problem-based learning group. Journal of Medical Imaging and Radiation Sciences, 46(3), 280-286. https://doi.org/10.1016/j.jmir.2015.06.007.

Rourke, L., Anderson, T., Garrison, D. R., \& Archer, W. (2001). Assessing social presence in asynchronous, text-based computer conferencing. Journal of Distance Education, 14(3), 51-70 Retrieved from https://core.ac.uk/download/pdf/58774853.pdf.

Saude, S., Puteh, F., Azizan, A. R., Hamdan, N. N., Shukor, N. H. A., \& Abdullah, K. I. (2012). Learning through the lounge: Using social presence to assess the learning environment in a MyLine online forum. Procedia - Social and Behavioral Sciences, 66(7), 448-459. https://doi.org/10.1016/j.sbspro.2012.11.289.

Schwandt, T. A. (1997). Qualitative inquiry: A dictionary of terms. Thousand Oaks: Sage.

Short, J., Williams, E., \& Christie, B. (1976). The social psychology of telecommunications. London: Wiley.

Smit, I., \& Goede, R. (2013). Dooyeweerd is watching you: Using instant messaging to prepare for assessment. In International Conference on e-Learning, (p. 386) Retrieved from https://repository.nwu.ac.za/handle/10394/13523. 
So, H. J., \& Brush, T. A. (2008). Student perceptions of collaborative learning, social presence and satisfaction in a blended learning environment: Relationships and critical factors. Computers \& Education, 51(1), 318-336. https://doi.org/10.1016/j. compedu.2007.05.009.

Sun, Z., Lin, C. H., Wu, M., Zhou, J., \& Luo, L. (2018). A tale of two communication tools: Discussion-forum and mobile instantmessaging apps in collaborative learning. British Journal of Educational Technology, 49(2), 248-261. https://doi.org/10. $1111 /$ bjet.12571.

Thomas, M. J. W. (2002). Learning within incoherent structures: The space of online discussion forums. Journal of Computer Assisted Learning, 18, 351-366. https://doi.org/10.1046/j.0266-4909.2002.03800.x.

Thomas, R. A., West, R. E., \& Borup, J. (2017). An analysis of instructor social presence in online text and asynchronous video feedback comments. The Internet and Higher Education, 33, 61-73. https://doi.org/10.1016/j.iheduc.2017.01.003.

Traphagan, T. W., Chiang, Y.-H. V., Chang, H. M., Wattanawaha, B., Lee, H., Mayrath, M. C., ... Resta, P. E. (2010). Cognitive, social and teaching presence in a virtual world and a text chat. Computers \& Education, 55(3), 923-936. https://doi.org/10. 1016/j.compedu.2010.04.003.

Tu, C. H., Mclsaac, M., Sujo-Montes, L., \& Armfield, S. (2013). Building mobile social presence for U-learning. In Technology Platform Innovations and Forthcoming Trends in Ubiquitous Learning, (p. 77). IGI Global. https://doi.org/10.4018/978-1-46668789-9.ch004.

Walther, J. B. (1992). Interpersonal effects in computer-mediated interaction: A relational perspective. Communication Research, 19(1), 52-90. https://doi.org/10.1177/009365092019001003.

Wang, Y., Fang, W. C., Han, J., \& Chen, N. S. (2016). Exploring the affordances of WeChat for facilitating teaching, social and cognitive presence in semi-synchronous language exchange. Australasian Journal of Educational Technology, 32(4), 18-37. https://doi.org/10.14742/ajet.2640.

Whiteside, A., Dikkers, A., \& Lewis, S. (2014). The power of social presence for learning. EDUCAUSE Review Online. Retrieved from https://er.educause.edu/articles/2014/5/the-power-of-social-presence-for-learning.

\section{Publisher's Note}

Springer Nature remains neutral with regard to jurisdictional claims in published maps and institutional affiliations.

\section{Submit your manuscript to a SpringerOpen ${ }^{\circ}$ journal and benefit from:}

- Convenient online submission

- Rigorous peer review

- Open access: articles freely available online

High visibility within the field

- Retaining the copyright to your article

Submit your next manuscript at $\boldsymbol{\nabla}$ springeropen.com 